\title{
L,Varying Chest Compression Rates During Neonatal Cardiopulmonary Resuscitation: A Randomized Controlled Animal Trial
}

\author{
Marlies Bruckner \\ Medical University of Graz \\ Mattias Neset BSc \\ University of Alberta \\ Catalina Garcia-Hidalgo \\ University of Alberta \\ Tze-Fun Lee \\ University of Alberta \\ Megan O'Reilly \\ University of Alberta \\ Po-Yin Cheung \\ University of Alberta \\ Georg M. Schmölzer ( $\square$ georg.schmoelzer@me.com ) \\ University of Alberta
}

\section{Research Article}

Keywords: chest compression, newborn piglets, asphyxia and cardiac arrest, Hemodynamic

Posted Date: December 17th, 2021

DOI: https://doi.org/10.21203/rs.3.rs-1153413/v1

License: (9) This work is licensed under a Creative Commons Attribution 4.0 International License. Read Full License 


\section{Abstract}

Background To compare chest compression (CC) rates of $90 /$ min with 180/min and their effect on the time to return of spontaneous circulation (ROSC), survival, hemodynamic, and respiratory parameters. We hypothesized that asphyxiated newborn piglets that received CC at 180/min vs. $90 /$ min during cardiopulmonary resuscitation would have a shorter time to ROSC.

Methods Newborn piglets ( $\mathrm{n}=7 /$ group) were anesthetized, intubated, instrumented and exposed to $45 \mathrm{~min}$ normocapnic hypoxia followed by asphyxia and cardiac arrest. Piglets were randomly allocated to a CC rate of $180 / \mathrm{min}$ or $90 / \mathrm{min}$. CC was performed using an automated chest compression machine. Hemodynamic and respiratory parameters and applied compression force were continuously measured.

Results The mean (SD) time to ROSC was 91 (34) and 256 (97) sec for CC rates of 180/min and 90/min, respectively $(p=0.08)$. The number of piglets that achieved ROSC was $7(100 \%)$ and $5(71 \%)$ with $180 / \mathrm{min}$ and $90 /$ min CC rates, respectively $(p=0.46)$. Hemodynamic parameters (i.e., diastolic and mean blood pressure, carotid blood flow, stroke volume, end-diastolic volume, left ventricular contractile function) and respiratory parameters (i.e., minute ventilation, peak inflation and peak expiration flow) were all improved with a CC rate of $180 / \mathrm{min}$.

Conclusion Time to ROSC and hemodynamic and respiratory parameters were all improved, with a CC rate of 180/min vs. 90/min. Higher CC rates during neonatal resuscitation warrant further investigation.

\section{Introduction}

Current neonatal resuscitation guidelines recommend a 3:1 compression to ventilation (C: $\mathrm{V})$ ratio with 90 chest compressions (CCs) and 30 inflations to achieve approximately 120 events per minute ${ }^{1,2}$. However, the optimal CC rate to optimize coronary and cerebral perfusion while providing adequate ventilation of an asphyxiated newborn remains unknown.

A mathematical study suggests that the most effective $\mathrm{CC}$ rate to optimize systemic perfusion depends upon body size and weight ${ }^{3}$. This would translate to CC rates of $180 / \mathrm{min}$ in term infants and higher rates for preterm infants. However, $\mathrm{CC}$ rates of $180 \mathrm{CC} / \mathrm{min}$ or above are impossible to achieve using a 3:1 C:V ratio. If a clear effect of body size and weight on the optimal compression frequencies for CPR exists, then optimizing compression frequencies for neonatal CPR has the potential to improve short- and longterm outcomes in newborn infants.

We aimed to examine different $\mathrm{CC}$ rates and their effect on the time to return of spontaneous circulation (ROSC), survival, and hemodynamic and respiratory parameters. We hypothesized that a CC rate of 180 /min compared to $90 /$ min during cardiopulmonary resuscitation would result in a shorter time to ROSC in asphyxiated newborn piglets.

\section{Results}


Fourteen newborn mixed breed piglets (0-3 days, weight 1.9-2.4 kg) were obtained on the day of the experiment and randomly assigned to a CC rate of $180 / \mathrm{min}(n=7)$ or $90 / \mathrm{min}(n=7)$. There were no differences in the baseline parameters or the start of CPR (end of asphyxia) between groups (Table 1). The median (IQR) duration of asphyxia was 470 (360-585) and 440 (280-506) sec in the 180/min and $90 /$ min CC groups, respectively $(p=0.65)$. Data separated by sex are presented in an online supplement.

\section{Resuscitation and primary outcome}

The mean (SD) time to ROSC was 91 (34) and 256 (97) sec for CC rates of 180/min and 90/min, respectively $(p=0.08)$. The number of piglets that achieved ROSC was $7(100 \%)$ and $5(71 \%)$ with $180 / \mathrm{min}$ and $90 / \mathrm{min} C \mathrm{C}$ rates, respectively $(p=0.46)$. Piglets receiving epinephrine were $2(29 \%)$ vs. $5(71 \%) p=0.29$ with 0 (0-1) and 1 (0-3) epinephrine boluses with CC rates of $180 / \mathrm{min}$ and $90 / \mathrm{min}$, respectively $(\mathrm{p}=0.08)$. The mean (SD) compression forces were $2.4(1)$ and $2.6(0.7) \mathrm{kg}$ at $90 \mathrm{CC} / \mathrm{min}$ and $180 \mathrm{CC} / \mathrm{min}$, respectively.

\section{Hemodynamic parameters}

Hemodynamic parameters at baseline and at commencement of resuscitation were not different (Table 1). Diastolic and mean blood pressure and carotid blood flow were significantly higher with a CC rate of $180 / \mathrm{min}$, while systolic blood pressure was not different between groups (Figure 2). Stroke volume and end-diastolic volume were improved, but this did not reach statistical significance (Figure 3 ), while $\mathrm{dp} / \mathrm{dt}_{\max }$ and $\mathrm{dp} / \mathrm{dt}_{\min }$ significantly improved with a CC rate of $180 /$ min (Figure 3 ).

\section{Respiratory parameters}

The tidal volume was not different between groups, while the minute ventilation was significantly increased with CC rate 180/min with mean (SD) 945 (249) compared to 522 (79) $\mathrm{mL} / \mathrm{kg} /$ with CC rate $90 /$ min group $(p=0.003$ ) (Table 2). Similarly, peak inflation flow and peak expiration flow were significantly higher with a CC rate of $180 / \mathrm{min}$ (Table 2 ).

\section{Discussion}

Current neonatal resuscitation guidelines recommend providing $90 \mathrm{CC}$ and 30 inflations $(=120$ events/minute) using a 3:1 C:V ratio to optimize cardiac output and oxygen delivery ${ }^{1,2}$. However, the optimal CC rate during neonatal CPR remains unclear. A mathematical study suggests that the most effective $\mathrm{CC}$ rate depends upon body size and weight and that higher $\mathrm{CC}$ rates, as currently recommended, might improve survival in newborn infants ${ }^{3}$. In the current study, we compared CC rates of $180 / \mathrm{min}$ and $90 / \mathrm{min}$ using CC+SI. The results of the study can be summarized as follows: using a CC rate of 180/min resulted in i) $30 \%$ higher survival; ii) $46 \%$ shorter time to ROSC; iii) less epinephrine 
administration; iv) higher blood pressure (diastolic and mean) and carotid blood flow (Figure 2); v) similar stroke volume and end-diastolic volume, and significantly improved left ventricular function (Figure 3 ); and vi) significantly increased minute ventilation and thereby oxygen delivery (Table 2).

Mathematical models described that the maximal cardiac output during CPR depends on the fraction of cycle time available for pump filling and pump emptying, with pump filling being dominant ${ }^{43}$. Fitzgerald et al compared CC rates between $20-140 / \mathrm{min}$ in 6-16 kg mongrel dogs and reported that the maximum cardiac output would be achieved with a CC rate of $126 / \mathrm{min}^{4}$. Similarly, a mathematical model by Babbs et al calculated the optimal CC rate to achieve maximum cardiac output with a CC rate of $124 / \mathrm{min}$ for a $10 \mathrm{~kg}$ child and 184/min for a $3 \mathrm{~kg}$ newborn infant, indicating a clear effect of body size and weight ${ }^{3}$. In the current study, stroke volume was higher at a CC rate of $180 /$ min (Figure 3), and as cardiac output is simple, the product of compression rate $\times$ stroke volume, cardiac output was also higher (results not shown).

The physiological heart rate in neonates ranges between $120-160 / \mathrm{min}^{5}$, and an increase in the CC rate might have the potential to boost artificial cardiac output compared to recommended CC rates, which are based largely on experimental work in animal models larger than neonates. Patel et a/ randomized asphyxiated piglets to continuous CC with asynchronized ventilation with CC rates of $90 / \mathrm{min}, 100 / \mathrm{min}$, and 120/min and reported similar mean times to ROSC of $90 \mathrm{sec}, 90 \mathrm{sec}$, and $120 \mathrm{sec}$, respectively ${ }^{6}$. Furthermore, the hemodynamic recovery (indicated by carotid blood flow and cerebral and renal perfusion) was similar between all three intervention groups ${ }^{6}$. Notably, the piglets in the $90 / \mathrm{min}$ and $100 /$ min groups had higher cerebral inflammation and brain injury than those in the 120/min group ${ }^{6}$. In comparison, Li et al reported a shortened median time to ROSC with a CC rate of $90 / \mathrm{min}$ compared with a CC rate of $120 / \mathrm{min}$ of $34 \mathrm{sec}$ versus $99 \mathrm{sec}^{7}$. However, CC with a higher rate had higher cardiac output and left ventricular function expressed by $\mathrm{dp} / \mathrm{dt}_{\max }$ and $\mathrm{dp} / \mathrm{dt}_{\mathrm{min}^{7}}$. Similarly, our own observations indicate that stroke volume, cardiac output, and left ventricular function increase with higher CC rates. Indeed, stroke volume and cardiac output were highest with a CC rate of $180 / \mathrm{min}$, while end-diastolic volume, $\mathrm{dp} / \mathrm{dt}_{\max }$ or $\mathrm{dp} / \mathrm{dt}_{\min }$ was highest at a CC rate of $150 / \mathrm{min}$. A further increase to a CC rate of $180 /$ min did not further increase the end-diastolic volume, $\mathrm{dp} / \mathrm{dt}_{\max }$ or $\mathrm{dp} / \mathrm{dt}_{\min }$. These data suggest that CC with a rate of 150-180/min might have optimal cardiovascular performance.

In the current study, we used a custom-designed chest compression machine ${ }^{8,9}$, which allowed consistent delivery of randomized CC rates. Furthermore, it reduced any potential bias (e.g., fatigue during CC or inability to constantly achieve allocated rate). Indeed, manikin studies compared CC rates of $90 / \mathrm{min}$ vs. 120 /min and observed higher fatigue and up to $50 \%$ decay in CC depth after 90 or 120 sec CC rate, respectively ${ }^{10,11}$. While we recognize that CPR using a CC rate of $180 / \mathrm{min}$ using a $3: 1 \mathrm{C}: \mathrm{V}$ ratio is nearly impossible, it might be feasible using continuous compressions.

In the current study, we used continuous CC during sustained inflation to examine different CC rates. Although continuous CC during sustained inflation is mentioned in the knowledge gap section of the 
neonatal resuscitation guidelines, it is currently not recommended ${ }^{1,2}$. Using the $3: 1 \mathrm{C}: \mathrm{V}$ ratio might have yielded other results. However, our automated CC machine can only provide continuous $\mathrm{CC}^{8,9}$.

\section{Limitations}

Our use of a piglet asphyxia model is a great strength of this translational study, as this model closely simulates delivery room events, with the gradual onset of severe asphyxia leading to bradycardia. Our asphyxia model uses piglets that have already undergone the fetal-to-neonatal transition, and piglets were sedated/anesthetized. Our model requires piglets to be intubated with a tightly sealed endotracheal tube to prevent endotracheal tube leak; this may not occur in the delivery room, as uncuffed endotracheal tubes are routinely used. A strength of this study is the use of our automated chest compression machine, which can apply high rates of $\mathrm{CC}^{6-9,11,13,14,17,19-28}$.

\section{Conclusion}

Time to ROSC and survival were improved with a CC rate of $180 /$ min compared to $90 / \mathrm{min}$. Respiratory and hemodynamic parameters were also improved with a CC rate of $180 / \mathrm{min}$ compared to $90 / \mathrm{min}$. A higher $\mathrm{CC}$ rate might improve organ perfusion and oxygen delivery compared to lower $\mathrm{CC}$ rates and warrants further investigation.

\section{Materials And Methods}

All experiments were conducted between January and November 2020 in accordance with the guidelines and approval of the Animal Care and Use Committee (Health Sciences), University of Alberta (AUP00001764), presented according to the ARRIVE guidelines ${ }^{12}$, and registered at preclincialtrials.eu (PTCE0000148). A graphical display of the study protocol is presented in Figure 1. The authors declare that all supporting data are available within the article.

\section{Randomization}

Piglets were randomly allocated to two groups ("CC rate $180 / \mathrm{min}$ or “90/min"). Randomization was 1:1 with variable block sizes using a computer-generated randomization program (http://www.randomizer.org). Sequentially numbered, sealed, brown envelopes containing the group allocation were opened during the experiment (Figure 1).

\section{Sample Size and Power Estimates}

The primary outcome measure was the time of CPR to achieve ROSC. Our previous studies showed a mean (standard deviation) ROSC of 220 (25) sec with a CC rate of $90 / \mathrm{min}$. We hypothesized that a CC rate of $180 / \mathrm{min}$ would reduce the time to achieve ROSC. A sample size of $7 /$ group would be sufficient to 
detect a clinically important (20\%) reduction in time to ROSC (i.e., $176 \mathrm{sec}$ vs. $220 \mathrm{sec}$ ) with $90 \%$ power and a 2-tailed alpha error of 0.05 .

\section{Blinding}

TFL opened the randomization envelope and set the rate on the automated CC machine. GMS assessed cardiac arrest and was blinded to group allocation prior to the start of CC. However, due to the varying acceleration speed of the plunger, blinding was not feasible during CC. The statistical analysis was blinded to group allocation and unblinded after completion.

\section{Inclusion and exclusion criteria}

Newborn mixed-breed piglets (0-3 days of age) obtained on the day of experimentation from the University Swine Research Technology Center were included. There were no exclusion criteria.

\section{Animal Preparation}

Piglets were instrumented as previously described with some modifications ${ }^{13}$. Following the induction of anesthesia using isoflurane, piglets were intubated via tracheostomy, and mechanical ventilation (Sechrist infant ventilator model IV-100; Sechrist Industries, Anaheim, CA) was commenced at a 20/min rate, peak inspiratory pressure of $25 \mathrm{cmH} 2 \mathrm{O}$ and positive end-expiratory pressure of $5 \mathrm{cmH} 2 \mathrm{O}$. Oxygen saturation was kept within 90-100\%, glucose level and hydration were maintained with an intravenous infusion of $5 \%$ dextrose at $10 \mathrm{~mL} / \mathrm{kg} / \mathrm{h}$. During the experiment, anesthesia was maintained with intravenous propofol $5-10 \mathrm{mg} / \mathrm{kg} / \mathrm{hr}$ and morphine $0.1 \mathrm{mg} / \mathrm{kg} / \mathrm{hr}$. Additional doses of propofol (1-2 $\mathrm{mg} / \mathrm{kg}$ ) and morphine $(0.05-0.1 \mathrm{mg} / \mathrm{kg}$ ) were also given as needed, and their body temperature was maintained at $38.5-39.5^{\circ} \mathrm{C}$ by using an overhead warmer and a heating pad.

\section{Hemodynamic Parameters}

A 5-French Argyle ${ }^{\circledR}$ (Klein-Baker Medical Inc. San Antonio, TX) double-lumen catheter was inserted into the femoral vein for fluid administration and medications. A 5-French Argyle ${ }^{\circledR}$ single-lumen catheter was inserted above the right renal artery via the femoral artery for continuous arterial blood pressure monitoring and arterial blood gas measurements. The right common carotid artery was exposed and encircled with a real-time ultrasonic flow probe (2 mm; Transonic Systems Inc., Ithica, NY) to measure carotid blood flow. A Millar catheter (MPVS Ultra, ADInstruments, Houston, TX) was inserted into the left ventricle (LV) via the left common carotid artery for continuous measurement of stroke volume, enddiastolic volumes, $\mathrm{dp} / \mathrm{dt}_{\max }$ (maximal rate of rise of left ventricular pressure), and $\mathrm{dp} / \mathrm{dt}_{\min }$ (minimum rate of change of ventricular pressure), which served as a surrogate for cardiac output. Because of the 
size difference between the Millar catheter and LV Iongitudinal axis, which poses a limitation for the accuracy of in vivo volume measurement, an alpha factor $=0.46$, based on comparison between Millar's recording and direct echocardiographic measurements in three piglets, was used to correct the conductance volume ${ }^{14}$.

Piglets were placed in the supine position and allowed to recover from surgical instrumentation until baseline hemodynamic measures were stable (minimum of one hour). The ventilator rate was adjusted to keep the partial arterial $\mathrm{CO}_{2}$ between $35-45 \mathrm{mmHg}$ as determined by periodic arterial blood gas analysis. Arterial blood pressure, heart rate, and percutaneous oxygen saturation were continuously measured and recorded throughout the experiment with a Hewlett Packard 78833B monitor (Hewlett Packard Co., Palo Alto, CA).

\section{Respiratory Parameters}

A respiratory function monitor (NM3, Respironics, Philips, Andover, MA) continuously measured tidal volume, airway pressures, gas flow, and end-tidal $\mathrm{CO}_{2}$. The sensor was placed between the endotracheal tube and the ventilation device. Tidal volume was calculated by integrating the flow signal, and end-tidal $\mathrm{CO}_{2}$ was measured using a nondispersive infrared absorption technique ${ }^{15,16}$. The accuracy for gas flow was $\pm 0.125 \mathrm{~L} / \mathrm{min}$, and the end-tidal $\mathrm{CO}_{2}$ was $\pm 2 \mathrm{mmHg}$.

\section{Automated Chest Compression Machine}

The settings for the automated CC machine were anterior-poster depth 33\%, acceleration of compression $500 \mathrm{~cm} / \mathrm{s} 2$, speed of recoil $50 \mathrm{~cm} / \mathrm{s}$, a simulated two-thumb technique, and a CC rate of $90 / \mathrm{min}$ or $180 / \mathrm{min}$ according to group allocation ${ }^{8,9}$.

\section{Force Measurement}

A FlexiForce A201 sensor (TekScan, Boston, MA) was placed on the bottom of the plunger of the automated CC machine to measure the applied compression force. The applied compression force was recorded with Arduino Software (Somervile, MA) with a sample rate of $200 \mathrm{~Hz}^{8,9}$.

\section{Experimental Protocol}

Piglets were randomized into two groups: "CC rate $180 / \mathrm{min}^{\text {" or }}$ "CC rate $90 / \mathrm{min}$ ". Following surgical instrumentation and stabilization, the piglets were placed onto the automated CC machine, which was placed on the surgical bed. The piglets' chest diameter was measured from the sternum to the vertebrae touching the bed (anterior to posterior) with a measuring tape, and then the anterior-posterior depth of 
$33 \%$ was calculated ${ }^{8,9}$. Piglets were then exposed to 45 minutes of normocapnic hypoxia, which was followed by asphyxia. Asphyxia was achieved by disconnecting the ventilator and clamping the endotracheal tube until asystole. Asystole was defined as zero carotid blood flow and no audible heartbeat during auscultation. Fifteen seconds after asystole, positive pressure ventilation was provided for $30 \mathrm{sec}$ with a Neopuff T-Piece (Fisher \& Paykel, Auckland, New Zealand) with 21\% oxygen, peak inspiratory pressure of $30 \mathrm{cmH} 2 \mathrm{O}$, positive end-expiratory pressure of $5 \mathrm{cmH} 2 \mathrm{O}$, and gas flow of $8 \mathrm{~L} / \mathrm{min}$. After $30 \mathrm{sec}$ of positive pressure ventilation, mechanical CC was initiated ${ }^{8,9}$ using $21 \%$ oxygen 17,18 , with an antero-posterior chest diameter depth of $33 \% 8,9$, and continuous $\mathrm{CC}$ was initiated during sustained inflation (CC+SI) with a peak inspiratory pressure of $30 \mathrm{cmH} 20$ for $30 \mathrm{sec}^{19-}$ 21. Sustained inflation was interrupted for $1 \mathrm{sec}$ before a further $30 \mathrm{sec}$ of sustained inflation was provided, and this was continued until ROSC ${ }^{13}$. Epinephrine $(0.02 \mathrm{mg} / \mathrm{kg}$ per dose) was administered intravenously 2 minutes after the start of positive pressure ventilation and every 3 minutes until ROSC with a maximum of three doses ${ }^{1,2}$, as the maximum resuscitation time was 10 minutes. The administration of epinephrine was immediately followed by a saline flush of $3 \mathrm{ml}$. ROSC was defined as an unassisted heart rate $>100 / \mathrm{min}$ for at least $15 \mathrm{sec}$. After ROSC, piglets recovered for one hour before being euthanized with an intravenous overdose of sodium pentobarbital $(120 \mathrm{mg} / \mathrm{kg})$. If there was no ROSC, piglets were euthanized immediately with an intravenous overdose of sodium pentobarbital (120 $\mathrm{mg} / \mathrm{kg}$ ).

\section{Data collection and statistical analysis}

Demographics of study piglets were recorded. Transonic flow probe, heart rate and pressure transducer outputs were digitized and recorded with LabChart ${ }^{\circledR}$ programming software (AD Instruments, Houston, TX). To analyze the hemodynamic data until time to ROSC (i.e., arterial blood pressure, central venous pressure, and carotid blood flow), the duration of $\mathrm{CC}$ time was divided into 10 epochs. To analyze stroke volume, end-diastolic volume, $\mathrm{dp} / \mathrm{dt}_{\mathrm{max}}$, and $\mathrm{dp} / \mathrm{dt}_{\mathrm{min}}$, the pressure-volume loops were compared between groups. Airway pressures, gas flow, tidal volume, and end-tidal $\mathrm{CO}_{2}$ were measured and analyzed using Flow Tool Physiologic Waveform Viewer (Philips Healthcare, Wallingford, CT, USA). For all respiratory parameters, the median values for each piglet during CPR were calculated first, and then the mean of the median was calculated for comparison.

The data are presented as the mean (standard deviation - SD) for normally distributed continuous variables and median (interquartile range - IQR) when the distribution was skewed. The data were tested for normality (Shapiro-Wilk and Kolmogorov-Smirnov test) and compared using t tests or rank sum for normally or skewed distributed data. $P$ values are 2 -sided, and $p<0.05$ was considered statistically significant. Statistical analyses were performed with SigmaPlot (Systat Software Inc, San Jose, USA).

\section{Abbreviations}




$\begin{array}{ll}\mathrm{CC} & \text { - Chest compression } \\ \mathrm{CC}+\mathrm{SI} & - \text { Continuous chest compressions during sustained inflations } \\ \mathrm{CPR} & - \text { Cardiopulmonary resuscitation } \\ \mathrm{CO} & - \text { Cardiac output } \\ \mathrm{C}: \mathrm{V} \text { ratio } & - \text { - Compression to ventilation ratio } \\ \text { ROSC } & \text { - Return of spontaneous circulation }\end{array}$

\section{Declarations}

\section{Author's contribution:}

Conception and design: PYC, MOR, TFL, GMS

Collection and assembly of data: PYC, MOR, TFL, GMS, MB, MN, CGH

Analysis and interpretation of the data: PYC, MOR, TFL, GMS, MB, MN, CGH

Drafting of the article: PYC, MOR, TFL, GMS, MB, MN, CGH

Critical revision of the article for important intellectual content: PYC, MOR, TFL, GMS, MB, MN, CGH

Final approval of the article: PYC, MOR, TFL, GMS, MB, MN, CGH

Conflict of Interest: None

\section{Funding sources}

We would like to thank the public for donating money to our funding agencies: The project was supported by a project grant from the Laerdal Foundation. GMS was a recipient of the Heart and Stroke Foundation/University of Alberta Professorship of Neonatal Resuscitation, a National New Investigator of the Heart and Stroke Foundation Canada and an Alberta New Investigator of the Heart and Stroke Foundation Alberta.

\section{References}

1. Aziz, K. et al. Part 5: Neonatal Resuscitation: 2020 American Heart Association Guidelines for Cardiopulmonary Resuscitation and Emergency Cardiovascular Care. Circulation 142, 1-27 (2020).

2. Wyckoff, M. H. et al. Neonatal Life Support: 2020 International Consensus on Cardiopulmonary Resuscitation and Emergency Cardiovascular Care Science With Treatment Recommendations. Circulation 142, 329-37 (2020). 
3. Babbs, C., Meyer, A. \& Nadkarni, V. Neonatal CPR: room at the top--a mathematical study of optimal chest compression frequency versus body size. Resuscitation 80, 1280-1284 (2009).

4. Fitzgerald, K. R., Babbs, C. F., Frissora, H. A., Davis, R. W. \& Silver, D. I. Cardiac output during cardiopulmonary resuscitation at various compression rates and durations. Am J Physiol-heart C 241, H442-H448 (1981).

5. Vrancken, S. L., Heijst, A. F. van \& Boode, W. P. de. Neonatal Hemodynamics: From Developmental Physiology to Comprehensive Monitoring. Frontiers in Pediatrics 6, 1366-15 (2018).

6. Patel, S. et al. Asynchronous ventilation at 120 compared with 90 or 100 compressions per minute improves hemodynamic recovery in asphyxiated newborn piglets. Archives Dis Child - Fetal Neonatal Ed 105, 357-363 (2020).

7. Li, E. S. et al. Return of spontaneous Circulation Is Not Affected by Different Chest Compression Rates Superimposed with Sustained Inflations during Cardiopulmonary Resuscitation in Newborn Piglets. PLOS ONE 11, e0157249 (2016).

8. Bruckner, M. et al. Assessment of optimal chest compression depth during neonatal cardiopulmonary resuscitation: a randomized controlled animal trial. Archives Dis Child - Fetal Neonatal Ed fetalneonatal-2021-321860 (2021) doi:10.1136/archdischild-2021-321860.

9. Bruckner, M. et al. Effects of varying chest compression depths on carotid blood flow and blood pressure in asphyxiated piglets. Archives Dis Child - Fetal Neonatal Ed fetalneonatal-2020-319473 (2021) doi:10.1136/archdischild-2020-319473.

10. Boldingh, A. M., Jensen, T. H., Bjørbekk, A. T., Solevåg, A. L. \& Nakstad, B. Rescuers' physical fatigue with different chest compression to ventilation methods during simulated infant cardiopulmonary resuscitation. J Maternal-fetal Neonatal Medicine 29, 1-6 (2015).

11. Li, E. S., Cheung, P.-Y., O'Reilly, M., Aziz, K. \& Schmölzer, G. M. Rescuer fatigue during simulated neonatal cardiopulmonary resuscitation. Nature Publishing Group 35, 142-145 (2015).

12. Kilkenny, C., Altman, D. G., Browne, W. J., Cuthill, I. C. \& Emerson, M. Improving Bioscience Research Reporting: The ARRIVE Guidelines for Reporting Animal Research. 8, e1000412 (2010).

13. Schmölzer, G. M. et al. Cardiopulmonary resuscitation with chest compressions during sustained inflations: a new technique of neonatal resuscitation that improves recovery and survival in a neonatal porcine model. Circulation 128, 2495-2503 (2013).

14. Wagner, M. et al. Effects of epinephrine on hemodynamic changes during cardiopulmonary resuscitation in a neonatal piglet model. Pediatric Research 83, 897-903 (2018).

15. Schmölzer, G. M. et al. Respiratory monitoring of neonatal resuscitation. Archives of Disease in Childhood-Fetal ... 95, F295-303 (2010).

16. Os, S. et al. Exhaled carbon dioxide can be used to guide respiratory support in the delivery room. Acta Paediatr 103, 796-806 (2014).

17. Garcia-Hidalgo, C. et al. Sustained inflation with $21 \%$ versus $100 \%$ oxygen during cardiopulmonary resuscitation of asphyxiated newborn piglets - A randomized controlled animal study. Resuscitation $155,39-47$ (2020). 
18. Garcia-Hidalgo, C., Cheung, P.-Y., Vento, M., O’Reilly, M. \& Schmölzer, G. M. A Review of Oxygen Use During Chest Compressions in Newborns-A Meta-Analysis of Animal Data. Frontiers in Pediatrics 6, S196-7 (2018).

19. Solevåg, A., Lee, T.-F., Lu, M., Schmölzer, G. M. \& Cheung, P.-Y. Tidal volume delivery during continuous chest compressions and sustained inflation. Archives of Disease in Childhood-Fetal ... 102, F85-F87 (2017).

20. Shim, G.-H. et al. Effects of sustained inflation pressure during neonatal cardiopulmonary resuscitation of asphyxiated piglets. PLOS ONE 15, e0228693-14 (2020).

21. Mustofa, J. et al. Effects of different durations of sustained inflation during cardiopulmonary resuscitation on return of spontaneous circulation and hemodynamic recovery in severely asphyxiated piglets. Resuscitation 129, 82-89 (2018).

22. Kim SY, Shim GH, O'Reilly M, Cheung PY, Lee TF, Schmölzer GM. Asphyxiated Female and Male Newborn Piglets Have Similar Outcomes With Different Cardiopulmonary Resuscitation Interventions. Front Pediatr. 2020 Dec 3;8:602228. doi: 10.3389/fped.2020.602228.

23. Solevåg AL, Garcia-Hidalgo C, Cheung PY, Lee TF, O'Reilly M, Schmölzer GM. Ventilation with 18, 21, or 100\% Oxygen during Cardiopulmonary Resuscitation of Asphyxiated Piglets: A Randomized Controlled Animal Trial. Neonatology. 2020;117(1):102-110. doi: 10.1159/000504494.

24. Patel S, Cheung PY, Lee TF, Pasquin MP, Lu M, O'Reilly M, Schmölzer GM. Asynchronous ventilation at 120 compared with 90 or 100 compressions per minute improves haemodynamic recovery in asphyxiated newborn piglets. Arch Dis Child Fetal Neonatal Ed. 2020 Jul;105(4):357-363. doi: 10.1136/archdischild-2018-316610.

25. Espinoza ML, Cheung PY, Lee TF, O'Reilly M, Schmölzer GM. Heart rate changes during positive pressure ventilation after asphyxia-induced bradycardia in a porcine model of neonatal resuscitation. Arch Dis Child Fetal Neonatal Ed. 2019 Jan;104(1):F98-F101. doi: 10.1136/archdischild-2017314637. Epub 2018 May 19. PMID: 29778994

26. Pasquin MP, Cheung PY, Patel S, Lu M, Lee TF, Wagner M, O'Reilly M, Schmölzer GM. Comparison of Different Compression to Ventilation Ratios (2: 1, 3: 1, and 4: 1) during Cardiopulmonary Resuscitation in a Porcine Model of Neonatal Asphyxia. Neonatology. 2018;114(1):37-45. doi: $10.1159 / 000487988$

27. Li ES, Görens I, Cheung PY, Lee TF, Lu M, O'Reilly M, Schmölzer GM. Chest Compressions during Sustained Inflations Improve Recovery When Compared to a 3:1 Compression:Ventilation Ratio during Cardiopulmonary Resuscitation in a Neonatal Porcine Model of Asphyxia. Neonatology. 2017;112(4):337-346. doi: 10.1159/000477998.

28. Schmölzer GM, O'Reilly M, Labossiere J, Lee TF, Cowan S, Nicoll J, Bigam DL, Cheung PY. 3:1 compression to ventilation ratio versus continuous chest compression with asynchronous ventilation in a porcine model of neonatal resuscitation. Resuscitation. 2014 Feb;85(2):270-5. doi: 10.1016/j.resuscitation.2013.10.011. 


\section{Tables}

Table 1: Characteristics of Newborn Piglets at Baseline and at Commencement of Cardiopulmonary Resuscitation 


\begin{tabular}{|c|c|c|c|}
\hline & CC rate $90 / \min (n=7)$ & CC rate $180 / \min (n=7)$ & $\mathrm{p}$ value \\
\hline \multicolumn{4}{|l|}{ Baseline characteristics } \\
\hline Age (days) & $2(1-3)$ & $3(1-3)$ & 0.81 \\
\hline Weight (kg) & $2.2(2.0-2.4)$ & $2.0(1.9-2.2)$ & 0.21 \\
\hline Heart rate (bpm) & $144(142-159)$ & $140(131-168)$ & 0.86 \\
\hline Mean Arterial blood pressure (mmHg) & $53(52-61)$ & $57(50-62)$ & 0.82 \\
\hline Carotid flow (mL/min) & $36(34-51)$ & $31(20-37)$ & 0.18 \\
\hline Cerebral oxygenation (\%) & $32(32-41)$ & $36(34-45)$ & 0.20 \\
\hline $\mathrm{pH}$ & $7.47(7.46-7.51)$ & $7.51(7.48-7.52)$ & 0.12 \\
\hline $\mathrm{PaO}_{2}$ (torr) & $62(61-90)$ & $62(55-71)$ & 0.46 \\
\hline $\mathrm{PaO}_{2}$ (torr) & $36.3(35.0-38.9)$ & $37.4(34.1-40.0)$ & 0.94 \\
\hline Base excess (mmol/L) & $3(2-4)$ & $4(3-7)$ & 0.17 \\
\hline Lactate (mmol/L) & $3.6(2.5-4.2)$ & $2.6(2.5-3.1)$ & 0.37 \\
\hline Duration of asphyxia (sec) & $440(280 \sim 506)$ & $470(360 \sim 585)$ & 0.65 \\
\hline \multicolumn{4}{|c|}{ Characteristics at commencement of Resuscitation } \\
\hline Heart rate (bpm) & $0(0-0)$ & $0(0-0)$ & \\
\hline Carotid blood flow (mL/min) & $0(0-0)$ & $0(0-0)$ & \\
\hline Arterial pH & $6.58(6.54-6.68)$ & $6.55(6.50-6.73)$ & 0.46 \\
\hline $\mathrm{paCO}_{2}$ (torr) & $102(67-121)$ & $106(86-112)$ & 0.68 \\
\hline Lactate (mmol/L) & $16(16-19)$ & $19(17-20)$ & 0.13 \\
\hline Base Excess (mmol/L) & $-29(-30 \sim-26)$ & $-28(-30 \sim-22)$ & 0.65 \\
\hline \multicolumn{4}{|c|}{ Characteristics immediately after return of spontaneous circulation } \\
\hline Heart rate (bpm) & $180(165-212)$ & $204(182-248)$ & 0.21 \\
\hline Carotid blood flow (mL/min) & $23(21-30)$ & $20(16-23)$ & 0.12 \\
\hline Arterial pH & $6.78(6.52-6.84)$ & $6.78(6.74-6.96)$ & 0.54 \\
\hline $\mathrm{paCO}_{2}$ (torr) & 50 (39-73) & $52(40-58)$ & 0.43 \\
\hline Lactate (mmol/L) & $20(18-20)$ & $20(20-20)$ & 0.36 \\
\hline Base Excess (mmol/L) & $-28(-30 \sim-26)$ & $-26(-29 \sim-25)$ & 0.38 \\
\hline
\end{tabular}




\begin{tabular}{|llll|}
\hline Heart rate $(\mathrm{bpm})$ & $190(152-219)$ & $206(192-241)$ & 0.19 \\
\hline Carotid blood flow (mL/min) & $29(25-39)$ & $33(18-39)$ & 0.87 \\
\hline Arterial pH & $7.02(6.93-7.19)$ & $7.12(6.97-7.24)$ & 0.65 \\
\hline paCO $_{2}$ (torr) & $37(33-57)$ & $33(28-44)$ & 0.64 \\
\hline Lactate (mmol/L) & $16(14-19)$ & $17(16-19)$ & 0.47 \\
\hline Base Excess (mmol/L) & $-20(-23 \sim-15)$ & $-20(-23 \sim-17)$ & 0.79 \\
\hline
\end{tabular}

Data are presented as median (IQR); $C$ C=chest compression

\section{Table 2: Respiratory parameters during CPR}

\begin{tabular}{|llll|}
\hline & $\begin{array}{c}\text { CC rate 90/min } \\
(\mathbf{n}=7)\end{array}$ & $\begin{array}{c}\text { CC rate 180/min } \\
(\mathbf{n}=7)\end{array}$ & p value \\
\hline Tidal volume $(\mathrm{mL} / \mathrm{kg})$ & $5.8(0.9)$ & $5.3(1.4)$ & 0.477 \\
\hline Minute Ventilation $(\mathrm{mL} / \mathrm{kg} / \mathrm{min})$ & $522(79)$ & $945(248)$ & 0.003 \\
\hline Peak Inspiratory Flow $(\mathrm{L} / \mathrm{min})$ & $3.7(0.4)$ & $5.8(0.9)$ & 0.0007 \\
\hline Peak Expiration Flow $(\mathrm{L} / \mathrm{min})$ & $-5.8(0.7)$ & $-8.0(0.7)$ & 0.0009 \\
\hline Peak Inflation Pressure $\left(\mathrm{cm} \mathrm{H}_{2} \mathrm{O}\right)$ & $30.0(1.5)$ & $31.1(4.2)$ & 0.546 \\
\hline Positive End Expiratory Pressure $\left(\mathrm{cm} \mathrm{H}_{2} \mathrm{O}\right)$ & $29.1(2.0)$ & $30.2(5.1)$ & 0.625 \\
\hline End-tidal CO 2 (mmHg) & $18(7)$ & $23(15)$ & 0.248 \\
\hline Rate $(/ \mathrm{min})^{*}$ & $90(1)$ & $179(1)$ & $<0.0001$ \\
\hline
\end{tabular}

Data are presented as the mean (SD), *Rate=Ventilation and number of chest compressions, which corresponds to the number of ventilations per minute; $\mathrm{CC}=$ chest compression

\section{Figures}




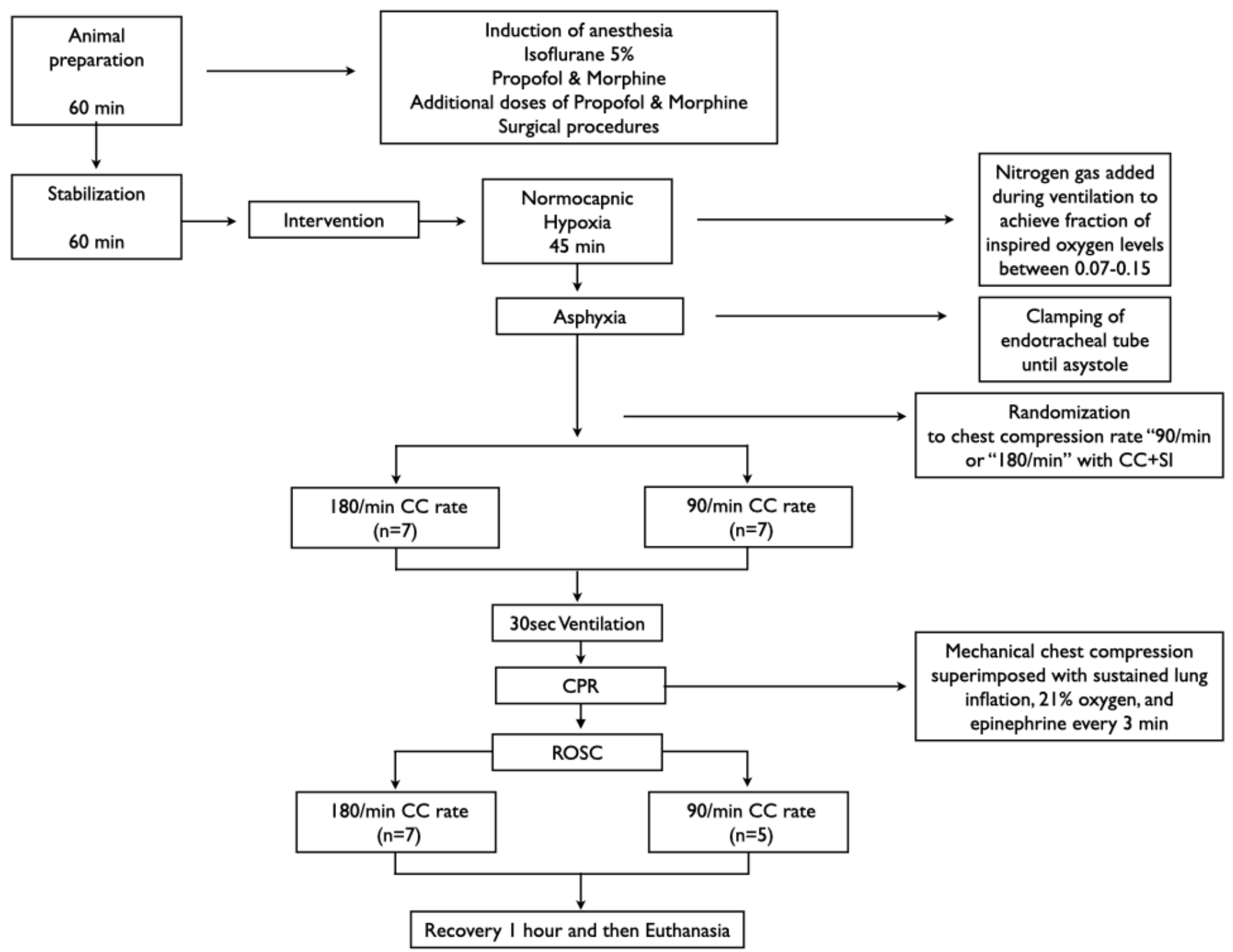

Figure 1

Study flow diagram 

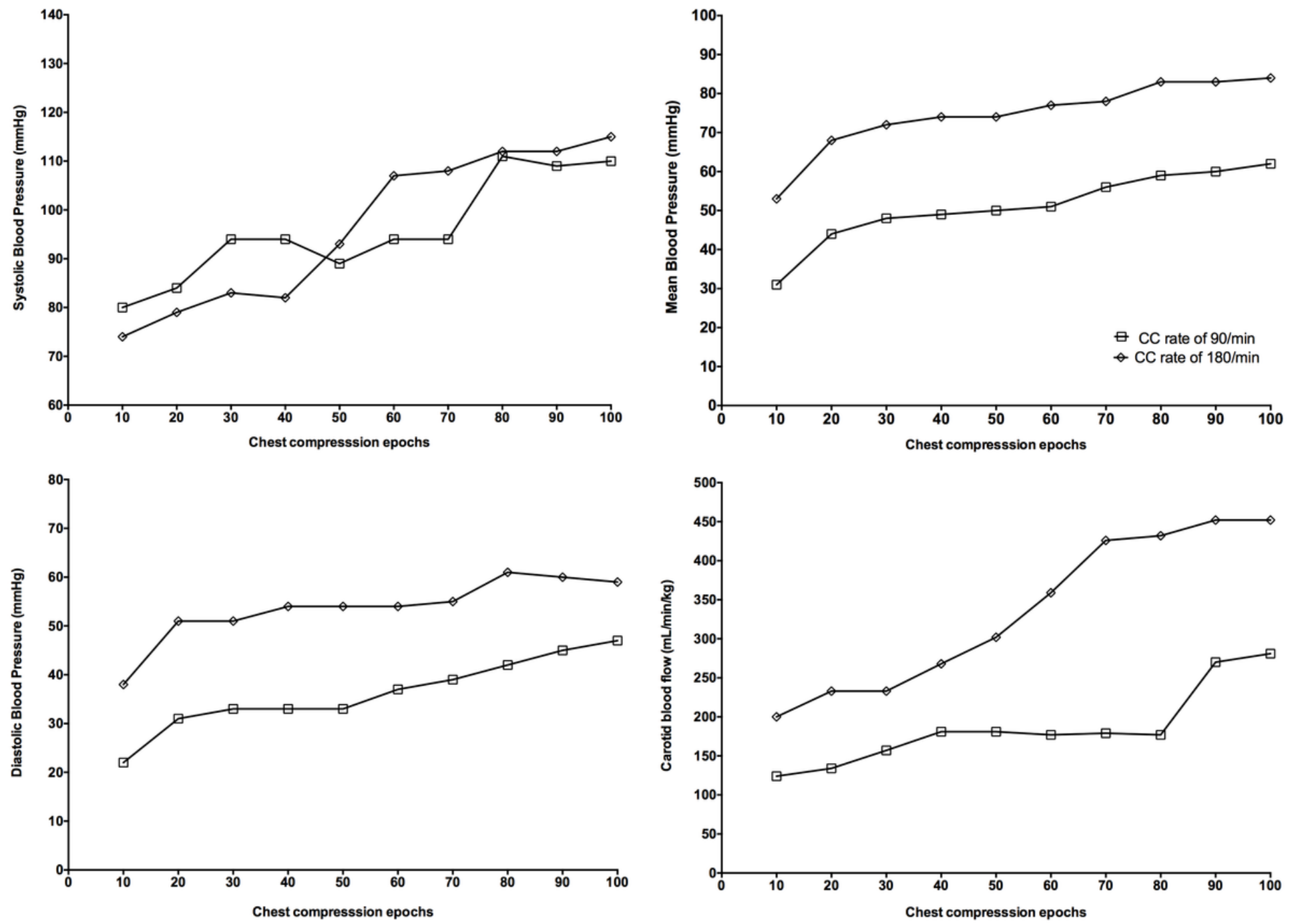

Figure 2

Changes in systolic blood pressure, diastolic blood pressure, mean blood pressure, and carotid blood flow during chest compression were divided into 10 epochs 

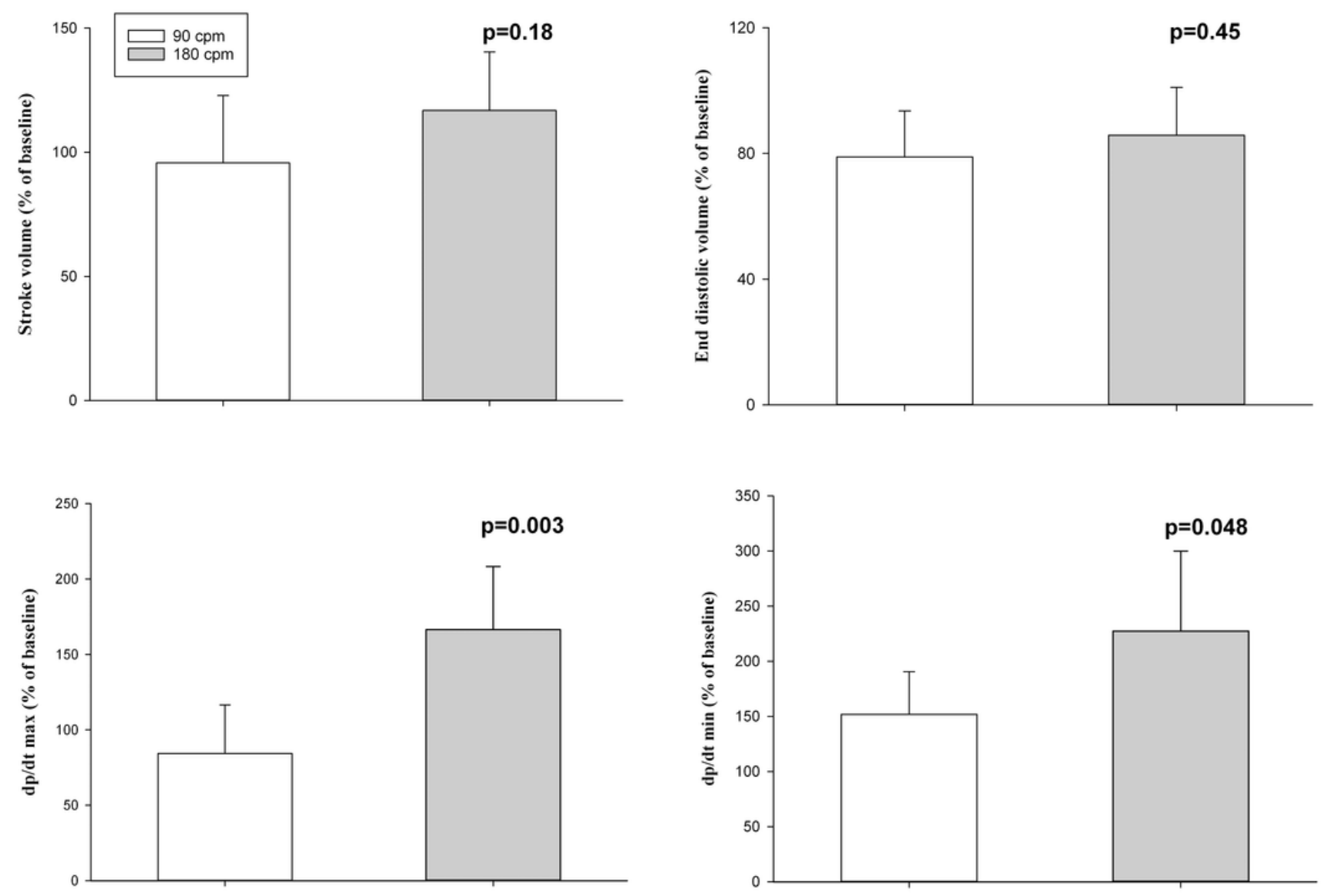

Figure 3

Stroke volume, end-diastolic volume, dp/dt max (maximal rate of rise of left ventricular pressure), and $\mathrm{dp} / \mathrm{dt}$ min (minimum rate of change of ventricular pressure)

\section{Supplementary Files}

This is a list of supplementary files associated with this preprint. Click to download.

- Onlinesupplement.pdf 